\title{
Trophic interactions and dynamic herbivore responses to snowpack
}

\author{
Jedediah F Brodie ${ }^{1 *}$, Eric Post ${ }^{2}$, Joel Berger ${ }^{3,4}$ and Fred Watson ${ }^{5}$
}

\begin{abstract}
Background: Trophic interactions and population structure can shape how climate change influences ecosystems by modifying herbivore responses to environmental conditions. Predation can influence herbivore behaviour and demography, but how changes in predation and population structure affect herbivore distribution across abiotic gradients remains little known. We assessed whether predators altered the response of different age and sex classes of a dominant ungulate herbivore to changing abiotic conditions.

Results: Elk (Cervus elaphus) presence declined with increasing snowpack, particularly in late winter when their body condition had deteriorated. Females and juveniles exhibited strong but constant negative responses to snowpack throughout the winter, although their mean occurrence declined over time likely due to sex-biased movement to lower elevations. Mature male occurrence responded only very slightly to snowpack and in a temporally invariant manner. Neither temporal nor spatial variation in wolf (Canis lupus) occurrence affected elk occurrence or elk responses to snowpack.

Conclusions: Climate change impacts on herbivore distribution in this system are driven by spatially and temporally dynamic interactions between winter conditions and population structure, but the influence of predation risk appears weak.
\end{abstract}

Keywords: Climate change, Herbivory, Population structure, Predation risk, Species interactions, Yellowstone

\section{Background}

Herbivore responses to changing abiotic conditions can have strong impacts on community structure. Changes in herbivore abundance or distribution may influence predator dynamics [1] and persistence [2]. Altered intensity or spatial distribution of herbivory can also affect plant abundance and diversity [3]. A more general understanding of how herbivore distribution, abundance, and foraging are affected by shifting abiotic conditions will greatly improve our knowledge of climate change impacts on natural ecosystems.

While we know generally that climate can strongly affect herbivore responses, we lack knowledge about which factors mediate herbivore distribution in relation to environmental conditions. Species interactions change with abiotic conditions [4], and not only directly alter herbivore abundance [5] and distribution [6], but also to change the way in

\footnotetext{
* Correspondence: brodie@biodiversity.ubc.ca

${ }^{1}$ Biodiversity Research Centre, Departments of Zoology and Botany,

University of British Columbia, Vancouver, BC V6T1Z4, Canada

Full list of author information is available at the end of the article
}

which herbivores respond to environmental conditions [7]. Indeed, novel outcomes of species interactions are among the most important factors to understand in attempting to predict community responses to climate change $[8,9]$.

Trophic interactions can strongly influence herbivore distribution and behavior and mediate herbivore impacts on plants. For instance, plant performance can be enhanced in areas that herbivores avoid due to high predation risk [10]. By affecting the spatial distribution of herbivores [11], predation risk also has the potential to shape how plant-herbivore interactions respond to changing abiotic conditions. For example, climate-induced habitat deterioration in habitat patches with high predation risk could potentially have no impact on herbivore distribution if the herbivores already avoided such locales.

Interactions between trophic relationships and abiotic conditions on herbivore distribution have seldom been demonstrated, however. One reason for this is that numerous factors influence herbivore distribution, so assessing interactions between trophic dynamics and climate requires untangling multiple concurrent impacts. Here 
we assess whether top-down and bottom-up interactions shape responses of a dominant ungulate herbivore along a gradient of abiotic conditions. We focus on elk because of their strong roles in affecting the demography and persistence of woody shrubs [12] that provide habitat for other species [13]. Previously, we demonstrated that the impact of elk herbivory on aspen (Populus tremuloides) in the Yellowstone Ecosystem is strongly affected by snow conditions [14]. Elk browse on aspen during the winter, yet avoid areas with deep or dense snow [14]. But determining whether elk responses to snowpack are mediated by trophic interactions requires a detailed analysis incorporating risk of wolf predation, changing elk body condition, and elk population structure. Wolf predation risk has been suggested to alter elk movements [15] and behavior [16] in ways that could potentially interact with the influence of snow conditions. Like other ungulates $[17,18]$, elk may face extended periods of food shortage during winter $[19,20]$, but their tolerance of deep snow may decrease over the winter as the enhanced energetic costs of movement become less affordable. Finally, there are likely important sex- and life stage-based differences in elk behavior [21]. Mature males are generally in worse body condition than females or juveniles at the start of winter from having expended bodily energetic reserves during the rut [cf. 22]; hence they may respond differently to predation risk, deep snow, or interactions among these factors.

We surveyed elk over two winters in Yellowstone along gradients in snow conditions and predation risk, assessing the effects of spatial as well as temporal variance in both snow conditions and predation risk. We hypothesized that the level of elk avoidance of deep snow areas will increase in response to several factors. First (prediction $i$ ), avoidance of snow would increase as winter progressed, because deteriorating body condition would increase energetic costs of movement. Second (prediction ii), avoidance would be higher for mature males, who started the winter in poorer body condition than females and juveniles because of the autumn rut. Third (prediction iii) avoidance would increase when wolves were in the immediate vicinity [16], because the higher energetic costs of predator-avoidance movements [23] and extra vigilance [cf. 24] would be unaffordable in combination with deep snow; this prediction is generated by the "landscape of fear" hypothesis, but we note that while elk are avoiding wolves, wolves are seeking out elk -these countervailing forces can potentially balance each other out. Finally (prediction $i v$ ) avoidance should increase in areas particularly frequented by wolves, since even temporary behavioral avoidance of wolves by elk [23] could potentially translate into permanent spatial differences in predation risk [25]. Predictions $(i)$ and (ii) relate to bottom-up influences and population structure, respectively. Predictions (iii) and (iv) relate to temporal and spatial variation in predation risk, respectively.

\section{Results}

Our survey covered 2,011 site-days in 2007-2008 and 2,839 site-days in 2008-2009. We recorded elk on 549 site-days across both sampling periods; mature males on 210 days, and females and juveniles on 376 days. Across sites, the average proportion of days on which elk were observed was $0.12(\mathrm{SD}=0.10$, range $=0.02: 0.43)$. We obtained 212 wolf photographs on 92 site-days. Elk were detected on $18.5 \%$ of the site-days on which wolves were also detected. Elk were detected on "wolf" days more often than expected by chance; for days when wolves were detected, the proportion of site-days when elk were also detected (0.19) was significantly higher than the proportion of total site-days on which elk were detected (0.12; two-sample proportion test, $Z=-2.15, p=0.03$ ).

We use snow water equivalent, the depth of the equivalent amount of liquid water contained in the snowpack, as a measure of snow conditions that integrates the depth and density of the pack. The maximum snow water equivalent averaged $15.0 \mathrm{~cm}$ (range $=1.68: 28.33$ ) across sites in 2007-2008 and $11.83 \mathrm{~cm}$ (range $=1.07: 23.10$ ) in 2008-2009. Pairwise correlations between predictor variables were $\mathrm{R}=0.33$ for winterday and swe, $|\mathrm{R}|<0.01$ for all other variable pairs.

Cross correlation analysis revealed no significant time lags in the effects of swe on elk presence, or of wolves on the presence of female and juvenile elk. Mature male elk presence was correlated with wolf relative abundance six eight days previously (Figure 1d). We used six-day lag effects for wolves on mature male elk in the temporallydynamic models below (but also present zero-lag model results in the SM).

Of the 253 models for temporal effects of snow, predation risk, and body condition, four received model support (i.e., Akaike weight $>0.00$; Tables 1 and 2). Using model averaging, six variables (including interaction terms) had unambiguous effects on elk occurrence (95\% confidence intervals (CIs) did not include zero): winterday, sex, winterday $\times$ swe, winterday $\times$ sex, swe $\times$ sex $)$, and winterday $\times$ swe $\times$ sex (Figure 2; Table 3). The model-averaged wolf coefficient was statistically negligible $(\beta<0.01 ; \mathrm{CI}=-0.01$ : $0.02)$. Occurrence by females and juveniles was substantially lower at high-SWE sites throughout the winter, while male occurrence was initially somewhat neutral, becoming slightly SWE-averse as winter progressed. The difference in response to SWE among sex and age classes was reduced over the course of the winter (Figure 2). The slope of the relationship with snow water equivalent stayed approximately constant for females and juveniles over the course of the winter ( -0.09 in January, -0.10 in April), while the intercept declined slightly more (0.14 in January to 0.12 in April). For mature males, the intercept stayed constant (0.04); the slope declined but remained close to zero throughout the winter (0.02 in January and -0.03 in April). 


\section{Lag (days)}

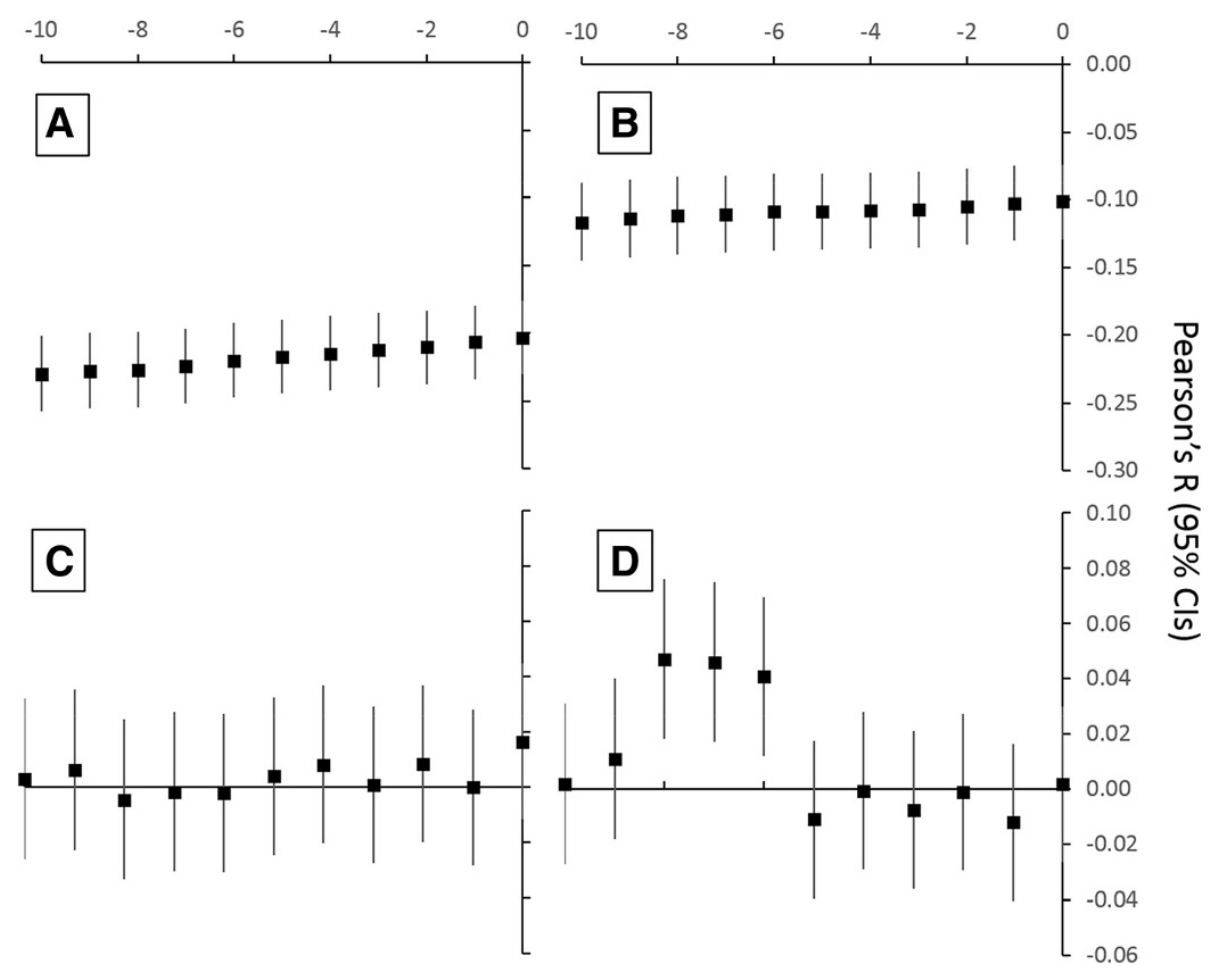

Figure 1 Correlation between elk presence and snow water equivalent for females \& juveniles (A) and mature males (B). Correlation between elk presence and wolf relative abundance for females \& juveniles (C) and mature males (D).

We assessed potential bias in our metric of predation risk by examining whether wolf conditional detectability (i.e., the probability of detection on days when the species is known to occur at a given site) varied with swe or winterday. The probabilities that models of wolf detectability containing swe or winterday were the most parsimonious were $<0.01$ and 0.01 , respectively.

Of the 24 models that we analyzed for spatial (i.e., temporally invariant) effects of snow and predation risk, 10 received model support, with one model receiving $52 \%$ of the support (Tables 2 and 4). Using model-averaging, only sex and the swe $\times$ sex interaction significantly related to elk site usage (i.e., CIs did not include zero; Figure 3). Elk site usage declined with increasing snowpack for females and juveniles but not mature males; site usage by neither females nor males responded to variation in wolf site usage.

\section{Discussion}

Temporal changes in trophic interactions, population structure, and herbivore responses to abiotic conditions help determine community responses to climate change. We presented four predictions of how responses to snowpack conditions by elk, the dominant ungulate herbivore in the Yellowstone Ecosystem, would be mediated by predation hazard, time (a proxy for body condition), and sex. Our first prediction, that elk would increasingly avoid snow as the winter progressed, which is associated with declining body condition, was supported. The probability

Table 1 Subset of the 253 temporally-dynamic models that had an AIC weight $>0.00$, without including any time-lags

\begin{tabular}{|c|c|c|c|c|c|c|c|c|c|c|}
\hline \multirow{2}{*}{$\begin{array}{l}\text { Number of } \\
\text { parameters }\end{array}$} & \multirow[t]{2}{*}{$\triangle \mathrm{AIC}$} & \multirow[t]{2}{*}{ AIC wt } & \multicolumn{8}{|c|}{ Coefficients (SE) } \\
\hline & & & Winterday & swe & Wolf & Sex & day $\times$ swe & day $\times$ sex & swexsex & day $\times$ swe $\times$ sex \\
\hline 8 & 0.00 & 0.62 & $-0.91(0.11)$ & $-0.13(0.15)$ & $n p$ & $0.36(0.12)$ & $-0.50(0.12)$ & $n p$ & $-0.70(0.14)$ & $-0.42(0.09)$ \\
\hline 9 & 1.72 & 0.26 & $-0.91(0.11)$ & $-0.13(0.15)$ & $0.02(0.03)$ & $0.36(0.12)$ & $-0.49(0.12)$ & $n p$ & $-0.70(0.14)$ & $-0.42(0.09)$ \\
\hline 8 & 4.19 & 0.08 & $-1.09(0.13)$ & $-0.13(0.15)$ & $n p$ & $0.42(0.13)$ & $-0.70(0.11)$ & $0.38(0.09)$ & $-0.65(0.14)$ & $n p$ \\
\hline 9 & 5.91 & 0.03 & $-1.09(0.13)$ & $-0.13(0.15)$ & $0.02(0.03)$ & $0.42(0.13)$ & $-0.70(0.11)$ & $0.38(0.09)$ & $-0.65(0.14)$ & $n p$ \\
\hline
\end{tabular}


Table 2 Subset of the 24 temporally-constant models of elk occurrence per 100 sampling days that had an AIC weight $>0.00$

\begin{tabular}{|c|c|c|c|c|c|c|c|c|c|}
\hline \multirow{2}{*}{$\begin{array}{l}\text { Number of } \\
\text { parameters }\end{array}$} & \multirow[t]{2}{*}{$\Delta \mathrm{AIC}$} & \multirow[t]{2}{*}{ AIC wt } & \multicolumn{7}{|c|}{ Coefficients (SE) } \\
\hline & & & swe & Wolf & Sex & swexwolf & swexsex & wolf xsex & swexwolf $\times$ sex \\
\hline 5 & 0.00 & 0.52 & $-0.02(2.16)$ & $n p$ & $11.30(3.00)$ & $n p$ & $-9.36(3.04)$ & $n p$ & $n p$ \\
\hline 6 & 2.56 & 0.15 & $-0.01(2.17)$ & $-0.53(1.54)$ & $11.30(3.04)$ & $n p$ & $-9.36(3.07)$ & $n p$ & $n p$ \\
\hline 7 & 2.99 & 0.12 & $0.01(2.14)$ & $-0.99(1.55)$ & $11.21(2.99)$ & $n p$ & $-9.62(3.03)$ & $n p$ & $3.19(2.18)$ \\
\hline 7 & 3.81 & 0.08 & $-0.15(2.16)$ & $-1.07(1.59)$ & $11.30(3.02)$ & $1.88(1.59)$ & $-9.36(3.06)$ & $n p$ & $n p$ \\
\hline 7 & 5.30 & 0.04 & $-0.02(2.20)$ & $-0.08(2.20)$ & $11.30(3.07)$ & $n p$ & $-9.33(3.11)$ & $-0.91(3.11)$ & $n p$ \\
\hline 8 & 5.55 & 0.03 & $-0.02(2.16)$ & $-0,08(2.16)$ & $11.20(3.02)$ & $n p$ & $-9.59(3.06)$ & $-1.90(3.12)$ & $3.47(2.25)$ \\
\hline 8 & 5.92 & 0.03 & $-0.04(2.17)$ & $-1.07(1.60)$ & $11.22(3.03)$ & $0.55(2.21)$ & $-9.58(3.08)$ & $n p$ & $2.67(3.06)$ \\
\hline 4 & 6.82 & 0.02 & $-4.70(1.70)$ & $n p$ & $11.30(3.30)$ & $n p$ & $\mathrm{np}$ & $n p$ & $n p$ \\
\hline 5 & 9.26 & 0.01 & $-4.68(1.69)$ & $-0.53(1.69)$ & $11.30(3.34)$ & $n p$ & $\mathrm{np}$ & $n p$ & $n p$ \\
\hline
\end{tabular}

Sex is coded as 1 for females and juveniles and 0 for mature males; $n p=$ not present in the model.

of male elk visiting a given site declined as snow accumulated over the course of the winter, particularly at sites with deep snowpack. This sex-based variance in responses to snowpack suggests that sex structure could importantly affect the mean response of a population to changing abiotic conditions.

Our second prediction, that avoidance of deep snow would be particularly strong in mature males due to their poor nutritional state following the autumn rut, was not supported. The probability of occurrence by males did respond to variation in snowpack, particularly from mid-March onwards, but the response of females and juveniles was consistently stronger. Females and juveniles are much more abundant in Yellowstone than mature males [26], leading to the higher model intercept for females and juveniles than males. But their occurrence drops much more rapidly in response to increasing snowpack depth, suggesting either that they die off rapidly or else move to lower elevations, such as outside the national park, as snow accumulation increases. It is

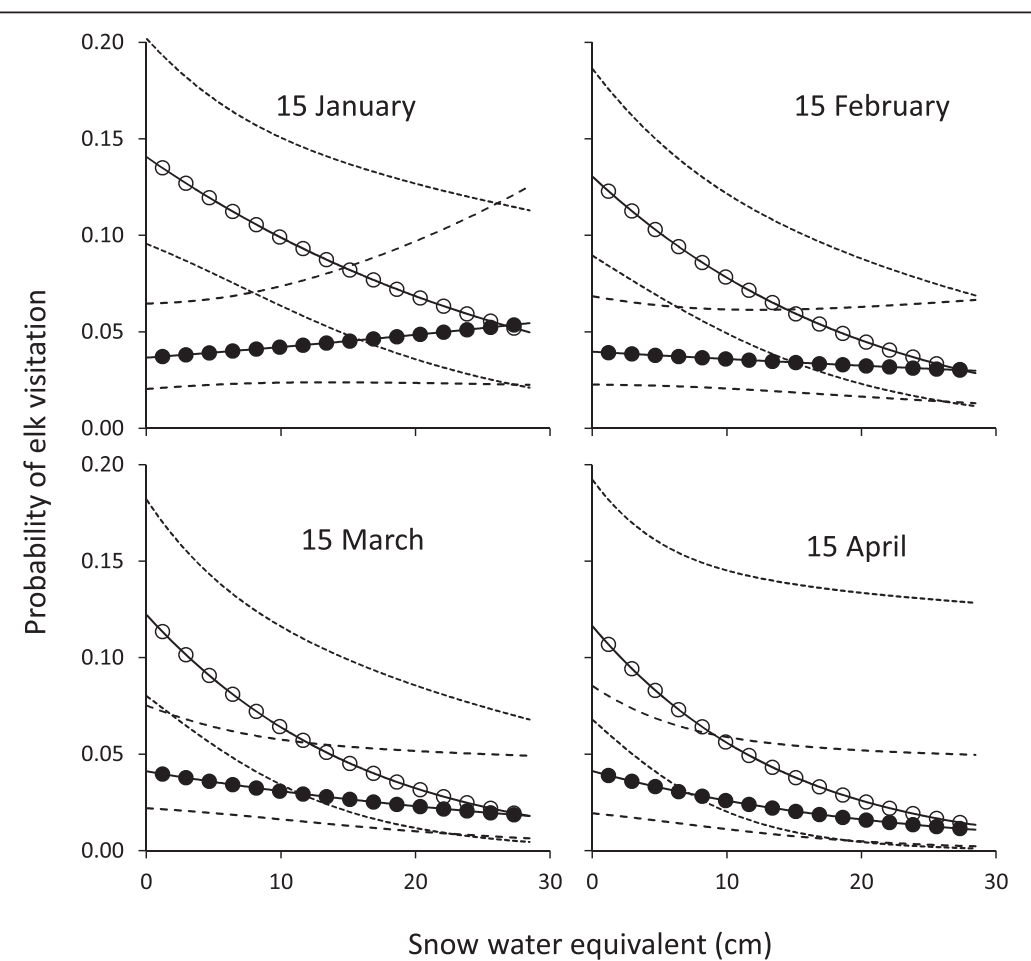

Figure 2 Model-averaged elk responses to snow for mature males (solid circles; dashed lines for $95 \%$ confidence intervals, Cls), and females and juveniles (open circles; dotted lines for Cls) over the course of the winter (with wolf held constant). Cls incorporate variance in fixed effects but not random effects. 
Table 3 Subset of the 253 temporally-dynamic models for daily probability of site occurrence by different elk that had an AIC weight $>0.00$

\begin{tabular}{|c|c|c|c|c|c|c|c|c|c|c|}
\hline \multirow{2}{*}{$\begin{array}{l}\text { Number of } \\
\text { parameters }\end{array}$} & \multirow[t]{2}{*}{$\triangle \mathrm{AIC}$} & \multirow[t]{2}{*}{ AIC wt } & \multicolumn{8}{|c|}{ Coefficients (SE) } \\
\hline & & & Winterday & swe & Wolf & Sex & day $\times s w e$ & day $\times$ sex & swexsex & day $\times$ swe $\times$ sex \\
\hline 8 & 0.00 & 0.58 & $-0.91(0.12)$ & $-0.13(0.12)$ & $n p$ & $0.32(0.13)$ & $-0.49(0.12)$ & $n p$ & $-0.75(0.15)$ & $-0.42(0.09)$ \\
\hline 9 & 1.93 & 0.22 & $-0.91(0.12)$ & $-0.13(0.12)$ & $0.01(0.03)$ & $0.32(0.13)$ & $-0.36(0.09)$ & $n p$ & $-0.75(0.15)$ & $-0.36(0.09)$ \\
\hline 8 & 2.82 & 0.14 & $-1.07(0.13)$ & $-0.15(0.12)$ & $n p$ & $0.39(0.13)$ & $-0.67(0.11)$ & $0.33(0.10)$ & $-0.70(0.14)$ & $n p$ \\
\hline 9 & 4.75 & 0.05 & $-1.09(0.13)$ & $-0.15(0.12)$ & $0.02(0.03)$ & $0.42(0.13)$ & $-0.70(0.11)$ & $0.38(0.09)$ & $-0.65(0.14)$ & $n p$ \\
\hline
\end{tabular}

Interaction terms are only shown if present in at least one of these models. Sex is coded as 1 for females and juveniles and 0 for mature males; $n p=$ not present in the model; wolf effect has a 6-day lag for mature male elk.

unlikely that females are dying off faster; elk survival studies show higher survival for females than males [27,28], though juvenile survival rates are lower than those of adults $[29,30]$. Because over-winter mortality of 1st-year juveniles is higher than that of adult females [30], the individual abundance of adult females + juveniles is likely to decline over the course of many winters. Our study, however, assessed occurrence rates of groups rather than abundance of individuals. Because 1st-year juveniles are not found away from adults during the winter, over-winter juvenile mortality probably does not explain the decline in detection rates of adult female + juvenile groups that we observed. Prior studies have shown that elk movement to lower elevations as the snow increases at high elevations [31], but we suggest that this movement is stronger for females than males. This could be due to higher tolerance of deep snow by males, perhaps because their larger body size facilitates digging for sub-nivean forage, they lack the energetic reserves, or they have a higher probability of avoiding encounters with wolves. Males may also opt to remain at higher elevations inside the park rather than leave the park and be exposed to trophy hunting by humans, though we note that adult female harvest rates adjacent to Yellowstone National Park have also been high [32]. It is also possible that elk daily mobility decreases in deep snow, which would reduce detection rate. We did not, however, detect an increase in the time spent at any given site in response to snow, as would be predicted if mobility were reduced.

Our last two predictions, that the level of avoidance of deep snow by elk would increase on days when wolves were present (temporal effects; prediction iii) or in sites where average wolf usage was higher (spatial effects; prediction $i v$ ), were not strongly supported. Though a wolf term was included in two of the top four temporallydynamic models, local wolf relative abundance had at best slight effects on the probability of elk occurrence at a given site on a given day. The model-averaged wolf coefficient was positive (in contrast to our predictions), very small (0.01), and its confidence intervals included

Table 4 Model-averaged parameter coefficients for relationship of different factors with elk occurrence (temporal models) or relative local abundance (spatial model); $n p=$ not present in the model

\begin{tabular}{|c|c|c|c|c|c|c|c|c|c|}
\hline \multirow[b]{2}{*}{ Parameter } & \multicolumn{3}{|c|}{ Temporal model (6-day lag for mature male elk) } & \multicolumn{3}{|c|}{ Temporal model (no time lags) } & \multicolumn{3}{|c|}{ Spatial model } \\
\hline & Mean & SE & $95 \% \mathrm{Cl}$ & Mean & SE & $95 \% \mathrm{Cl}$ & Mean & SE & $95 \% \mathrm{Cl}$ \\
\hline Winterday & -0.93 & 0.12 & $-1.16:-0.71$ & -0.92 & 0.11 & $-1.15:-0.70$ & $n p$ & & \\
\hline SWE & -0.13 & 0.12 & $-0.36: 0.10$ & -0.13 & 0.11 & $-0.35: 0.09$ & -0.16 & 2.15 & $-4.37: 4.04$ \\
\hline Wolf & 0.00 & 0.01 & $-0.01: 0.02$ & 0.01 & 0.01 & $-0.01: 0.02$ & -0.32 & 0.75 & $-1.80: 1.15$ \\
\hline Sex & 0.33 & 0.13 & $0.08: 0.58$ & 0.36 & 0.12 & $0.13: 0.60$ & 11.28 & 3.02 & $5.36: 17.20$ \\
\hline Winterday $\times$ SWE & -0.49 & 0.11 & $-0.71:-0.28$ & -0.51 & 0.11 & $-0.74:-0.29$ & $n p$ & & \\
\hline Winterday $\times$ wolf & 0.00 & 0.00 & $0.00: 0.00$ & 0.00 & 0.00 & $0.00: 0.00$ & $n p$ & & \\
\hline Winterday $\times$ sex & 0.07 & 0.02 & $0.03: 0.10$ & 0.04 & 0.01 & $0.02: 0.06$ & $n p$ & & \\
\hline SWE $\times$ Wolf & 0.00 & 0.00 & $0.00: 0.00$ & 0.00 & 0.00 & $0.00: 0.00$ & 0.17 & 0.19 & $-0.21: 0.54$ \\
\hline SWE $\times$ sex & -0.73 & 0.14 & $-1.01:-0.45$ & -0.69 & 0.14 & $-0.96:-0.41$ & -9.13 & 2.96 & $-14.92:-3.33$ \\
\hline Wolf $x$ sex & 0.00 & 0.00 & $0.00: 0.00$ & 0.00 & 0.00 & $0.00: 0.00$ & -0.09 & 0.22 & $-0.52: 0.33$ \\
\hline Winterday $\times$ SWE $\times$ wolf & 0.00 & 0.00 & $0.00: 0.00$ & 0.00 & 0.00 & $0.00: 0.00$ & $n p$ & & \\
\hline Winterday $\times$ SWE $\times$ sex & -0.33 & 0.08 & $-0.47:-0.18$ & -0.37 & 0.08 & $-0.54:-0.21$ & $n p$ & & \\
\hline Winterday $\times$ wolf $\times$ sex & 0.00 & 0.00 & $0.00: 0.00$ & 0.00 & 0.00 & $0.00: 0.00$ & $n p$ & & \\
\hline SWE $\times$ wolf $\times$ sex & 0.00 & 0.00 & $0.00: 0.00$ & 0.00 & 0.00 & $0.00: 0.00$ & 0.56 & 0.42 & $-0.26: 1.38$ \\
\hline
\end{tabular}




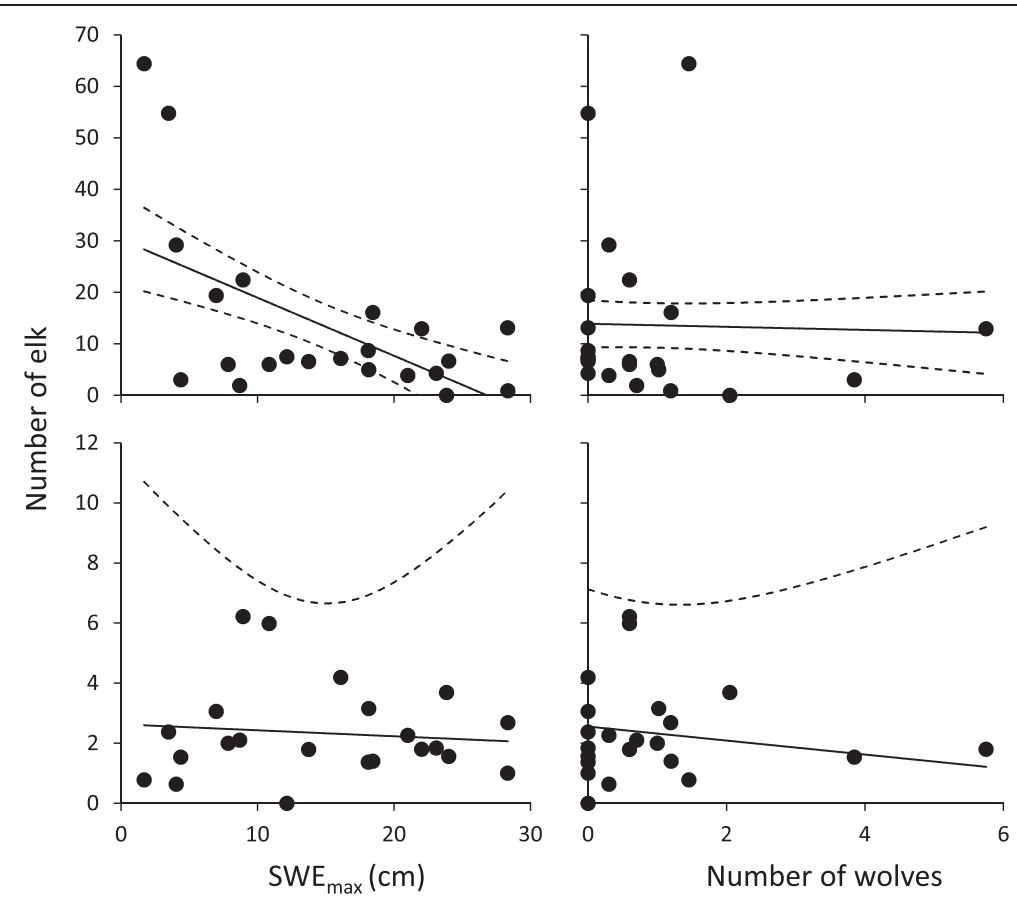

Figure 3 Number of elk detected per 100 days at each site, averaged over 2007-2009, fit with model-averaged trendlines (solid lines, with $95 \%$ confidence limits as dashed lines) for snow effects (left column; maximum snow water equivalent, "SWE", at each site) and wolf effects (right column; number of wolves detected per 100 days). Effects for females and juveniles in the top row and mature males in the bottom row.

zero. It is possible that wolves and elk avoid deep snowpack equally. We had a reasonably large wolf sample size with which to have detected a wolf effect had it existed, and our use of temporally-lagged models for mature male elk should have further increased our ability to detect wolf effects. Though our sample size still might not have been big enough to statistically detect a wolf effect, we maintain that this in itself is biologically meaningful -wolf abundance in Yellowstone peaked at or just before the time of this study [33]. If we were unable to detect a wolf effect then, we probably would not have detected one before or since. We note that our metric of predation risk almost certainly underestimates true wolf usage of each site because camera traps are imperfect at detecting any species. However, we found that wolf conditional detection probability (using temporal sub-sampling) did not vary with snow water equivalent or time, suggesting that relative site usage is an unbiased index of true site usage by wolves.

Effects of predation risk on herbivore behavior are difficult to assess non-experimentally. On the one hand, the "landscape of fear" hypothesis predicts that herbivores avoid sites where predators are most active, theoretically leading to a negative relationship between predator and prey abundance. Nevertheless, predators track their prey and are likely to be more concentrated where prey base is highest [34], theoretically generating positive predator- prey relationships. These opposing forces potentially cancel each other out [35], possibly explaining the flat relationship between wolf and elk site usage that we observed here. We noted a potential signal of wolves tracking elk; the twosample proportion test suggested that elk were detected on "wolf" days more often than expected by chance. However, this positive relationship disappeared in the logistic models that include other fixed effects as well as a random effect. Thus wolves and elk do not appear to conform to the simple dynamics proposed by the "landscape of fear" hypothesis, whereby prey avoidance of predators generates spatially- and temporally- consistent negative relationships between predation risk and prey abundance. Indeed it remains unclear how more nuanced predator-prey dynamics would influence herbivory intensity or plant performance. We note, however, that the growth of aspen in Yellowstone is not detectably reduced by wolf-induced predation risk $[12,14]$ [also see [23] for similar results for other shrub species].

Our results have implications for understanding climate change effects on the Yellowstone Ecosystem. As a dominant herbivore, elk can strongly influence plant distribution and persistence [14]. This herbivory can be regulated by snowpack conditions, which are changing as western North America warms and dries [36]. As we show, elk responses to snow are mediated by sex and (weakly) time, the latter likely a proxy for body condition. This suggests 
that managers can influence winter spatial variation in elk abundance -and therefore the intensity of elk herbivoryby altering the sex ratio of the herd via sex-specific hunting quotas. If the relative proportion of mature males declines, the average response to snowpack across the population may grow stronger, meaning that plants at high-elevation sites are subject to lower cumulative herbivory. Moreover, assuming that the increased avoidance of deep snow in later winter is in fact due to deteriorating elk body condition, summer plant productivity could influence winter herbivory. Multiple interacting factors, all of which are nuanced and imperfectly understood, affect patterns of herbivory. Increasing our still-limited understanding of these factors and their interactions will greatly enhance our knowledge about climate change impacts on communities.

\section{Methods}

\section{Sampling methods}

We deployed heat- and motion-triggered camera traps in aspen stands across northern Yellowstone over the course of two winters to detect elk and wolf occurrence at specific sites. We sampled 22 sites in total; 17 in 2007-2008 and 18 in 2008-2009. Winter (November - May) and summer (June - August) Palmer Drought Severity Index for Wyoming was -4.43 and -6.96 , respectively, in the first field season and -3.35 and -3.14 , respectively in the second field season; the 1990-2010 average for Wyoming was -3.56 (winter) and -3.48 (summer). Sites for camera deployment were selected out of a larger sample of randomly-selected aspen stands used in Brodie et al. [14]; sites were chosen to straddle gradients in snow conditions (i.e., determined mainly by elevation, aspect, and conifer forest cover), but with no prior knowledge of elk usage. We also had no prior knowledge of wolf usage at any of the sites, although the stands we sampled spanned a gradient in predation risk [25].

\section{Analysis}

To assess temporal effects of bottom-up and top-down influences while accounting for elk population structure (predictions $i$ - iii), we used generalized linear mixed models with logit link functions to measure the daily probability of site occurrence by different elk sex- and life-stages. The predictor variables we examined were: snow water equivalent ("swe") from the Langur Yellowstone snow model [37], "winter day", a continuous variable starting with 1 on the first day of winter (here taken to be 15 November), and proceeding to 30 April, "wolf", or the number of wolves photographed at each site on each day, and "sex", 0 for mature males and 1 for females and immature males; mature males were identified in photographs by their antlers throughout early and mid-winter, and prominent pedicels after antler shedding in March. Daily wolf detections serve as a simple and transparent proxy for predation risk that, on the one hand, ignores habitat influences that can modify wolf-elk interactions [cf. 25] but, on the other hand, is temporally dynamic rather than static. All models had "site" as a random effect and standardized continuous variables. We incorporated interaction terms: a winterday $\times$ swe interaction to test prediction $i$, a swe $\times$ sex interaction for prediction $i i$, and a swe $\times$ wolf interaction for prediction iii. We used cross correlation analysis to identify significant time lags in the effects of swe and wolf on elk [cf. 38].

We used model selection to determine which variables and interactions were related to elk distribution. We examined models representing all combinations of the four main effect variables and their interactions. Interactions could be among two or three variables but not all four, and models could contain a maximum of three interaction terms.

To assess potential bias in our metric of predation risk, we tested whether wolf conditional detection probability (a "nuisance parameter" separate from the relative site usage metric of biological interest) varied with swe or winterday. We used temporal sub-sampling, regressing the arcsine-transformed proportion of hours on which wolves were detected on days on which they were detected at least once against swe or winterday. This is analogous to how hierarchical "occupancy models" e.g., [39] measure detectability in order to partition it from state variables of biological interest. Our models included site as a random effect. We measured the relative probability that the wolf model minimized the estimated information loss by calculating $\exp \left(\left(\mathrm{AIC}_{\min }-\mathrm{AIC}_{\max }\right) / 2\right)$, where $\mathrm{AIC}_{\text {min }}$ and $\mathrm{AIC}_{\max }$ were the lowest and highest $\mathrm{AIC}$ values from model sets containing either a swe or a winterday model and an intercept-only model.

To assess how temporally-invariant spatial variation in snowpack, predation risk, sex, and their interactions affected elk, we used simple linear models. We measured elk and wolf relative site usage as the total number of each species observed per 100 sampling days, averaged across the two winters. The snow term in these models was the maximum estimated snow water equivalent at each site, as this represents the largest potential deterrent to site usage by elk and has been shown in prior studies [14] to relate to the probability of elk occurrence.

\section{Abbreviations}

AIC: Akaike Information Criterion; Cl: Confidence interval; SWE: Snow water equivalent.

\section{Competing interests}

The authors declare that they have no competing interests.

\section{Authors contributions}

JB conceived of the study, conducted the field work and data analysis, and drafted the initial manuscript. EP and JB participated in the design of the study. FW conducted the snow model analysis. All authors helped revise the manuscript and approved the final version. 


\section{Acknowledgements}

Funding came from the David Smith Research Fellowship (Cedar Tree Foundation and Society for Conservation Biology) and the U.S. Geological Survey.

\section{Author details}

${ }^{1}$ Biodiversity Research Centre, Departments of Zoology and Botany, University of British Columbia, Vancouver, BC V6T1Z4, Canada. ²Department of Biology, Pennsylvania State University, State College, PA 16802, USA. ${ }^{3}$ Organismal Biology and Ecology Program, University of Montana, Missoula, MT 59812, USA. ${ }^{4}$ Wildlife Conservation Society, Northern Rockies Field Office, University of Montana, Missoula, MT 59812, USA. ${ }^{5}$ Division of Science and Environmental Policy, California State University Monterey Bay, Seaside, CA 93955, USA.

Received: 30 December 2013 Accepted: 29 May 2014

Published online: 22 October 2014

\section{References}

1. Wirsing AJ, Heithaus MR, Dill LM: Can measures of prey availability improve our ability to predict the abundance of large marine predators? Oecologia 2007, 153:563-568.

2. Penteriani V, Otalora F, Ferrer M: Floater survival affects population persistence. The role of prey availability and environmental stochasticity. Oikos 2005, 108:523-534.

3. Maron $J$, Crone E: Herbivory: effects on plant abundance, distribution and population growth. Proceedings of the Royal Society B-Biological Sciences 2006, 273:2575-2584.

4. Tylianakis JM, Didham RK, Bascompte J, Wardle DA: Global change and species interactions in terrestrial ecosystems. Ecol Lett 2008, 11:1351-1363.

5. Brodie J, Johnson H, Mitchell M, Zager P, Proffitt K, Hebblewhite M, Kauffman M, Johnson B, Bissonette J, Bishop C, Gude J, Herbert J, Hersey K, Hurley M, Lukacs P, McCorquodale S, McIntire E, Nowak J, Sawyer H, Smith D, White PJ: Relative influence of human harvest, carnivores, and weather on adult female elk survival across western North America. J Appl Ecol 2013, 50:295-305.

6. Harley CDG: Climate change, keystone predation, and biodiversity loss. Science 2011, 334:1124-1127.

7. Mclntosh AR, Peckarsky BL, Taylor BW: Predator-induced resource heterogeneity in a stream food Web. Ecology 2004, 85:2279-2290.

8. Post E: Erosion of community diversity and stability by herbivore removal under warming. Proceedings of the Royal Society B-Biological Sciences 2013, 280. doi:10.1098/rspb.2012.2722.

9. Singer A, Travis JMJ, Johst K: Interspecific interactions affect species and community responses to climate shifts. Oikos 2013, 122:358-366.

10. Krivan V, Schmitz OJ: Trait and density mediated indirect interactions in simple food webs. Oikos 2004, 107:239-250.

11. Schmitz OJ, Grabowski JH, Peckarsky BL, Preisser EL, Trussell GC, Vonesh JR: From individuals to ecosystem function: toward an integration of evolutionary and ecosystem ecology. Ecology 2008, 89:2436-2445.

12. Kauffman MK, Brodie JF, Jules E: Are wolves saving Yellowstone's aspen? A landscape-level test of a behaviorally mediated trophic cascade. Ecology 2010, 91:2742-2755.

13. DeByle NV: Wildlife. In Aspen: Ecology and Management in the Western United States. Edited by DyByle NV, Winokur RP. Fort Collins, CO, USA: US Department of Agriculture Forest Service General Technical Report RM-119; 1985.

14. Brodie J, Post E, Watson F, Berger J: Climate change intensification of herbivore impacts on tree recruitment. Proceedings of the Royal Society B-Biological Sciences 2012, 279:1366-1370.

15. Ripple WJ, Larsen EJ, Renkin RA, Smith DW: Trophic cascades among wolves, elk and aspen on Yellowstone National Park's northern range. Biol Conserv 2001, 102:227-234.

16. Berger J: Carnivore repatriation and holarctic prey: narrowing the deficit in ecological effectiveness. Conserv Biol 2007, 21:1105-1116.

17. Delgiudice GD, Seal US, Mech LD: Indicators of severe undernutrition in urine of free-ranging elk during winter. Wildl Soc Bull 1991, 19:106-110.

18. Parker KL, Barboza PS, Stephenson TR: Protein conservation in female caribou (Rangifer tarandus): effects of decreasing diet quality during winter. J Mammal 2005, 86:610-622.

19. Christianson D, Creel S: A nutritionally mediated risk effect of wolves on elk. Ecology 2010, 91:1184-1191.
20. Hobbs NT, Baker DL, Ellis JE, Swift DM, Green RA: Energy-based and Nitrogen-based estimates of elk winter-range carrying-capacity. J Wildl Manag 1982, 46:12-21

21. Winnie J, Creel S: Sex-specific behavioural responses of elk to spatial and temporal variation in the threat of wolf predation. Anim Behav 2007, 73:215-225.

22. McLellan ML, Serrouya R, McLellan BN, Furk K, Heard DC, Wittmer HU: Implications of body condition on the unsustainable predation rates of endangered mountain caribou. Oecologia 2012, 169:853-860.

23. Creel S, Christianson D: Wolf presence and increased willow consumption by Yellowstone elk: implications for trophic cascades. Ecology 2009, 90:2454-2466

24. Liley S, Creel S: What best explains vigilance in elk: characteristics of prey, predators, or the environment? Behav Ecol 2008, 19:245-254.

25. Kauffman MK, Varley N, Smith DW, Stahler DR, MacNulty DR, Boyce MS: Landscape heterogeneity shapes predation in a newly restored predator-prey system. Ecol Lett 2007, 10:690-700.

26. Smith DW, Drummer TD, Murphy KM, Guernsey DS, Evans SB: Winter prey selection and estimation of wolf kill rates in Yellowstone National Park, 1995-2000. J Wildl Manag 2004, 68:153-166.

27. McCorquodale SM, Wik PA, Fowler PE: Elk survival and mortality causes in the blue mountains of Washington. J Wildl Manag 2011, 75:897-904.

28. McCorquodale SM, Wiseman R, Marcum CL: Survival and harvest vulnerability of elk in the cascade range of Washington. J Wildl Manag 2003, 67:248-257.

29. Raithel JD, Kauffman MJ, Pletscher DH: Impact of spatial and temporal variation in calf survival on the growth of elk populations. J Wildl Manag 2007, 71:795-803.

30. Garrott RA, Eberhardt LL, Rotella J, White PJ: Climate-induced variation in vital rates of an unharvested large-herbivore population. Can J Zool 2003, 81:33-45.

31. White PJ, Proffitt KM, Mech LD, Evans SB, Cunningham JA, Hamlin K: Migration of northern Yellowstone elk: implications of spatial structuring. J Mammal 2010, 91:827-837.

32. White PJ, Garrott RA: Northern Yellowstone elk after wolf restoration. Wildl Soc Bull 2005, 33:942-955.

33. Almberg ES, Cross PC, Dobson AP, Smith DW, Hudson PJ: Parasite invasion following host reintroduction: a case study of Yellowstone's wolves. Philosophical Transactions of the Royal Society B-Biological Sciences 2012, 367:2840-2851.

34. Ngoprasert D, Lynam AJ, Sukmasuang R, Tantipisanuh N, Chutipong W, Steinmetz R, Jenks KE, Gale GA, Grassman LI, Kitamura S, Howard J, Cutter P, Leimgruber $\mathrm{P}$, Songsasen $\mathrm{N}$, Reed $\mathrm{DH}$ : Occurrence of three felids across a network of protected areas in Thailand: prey, intraguild, and habitat associations. Biotropica 2012, 44:810-817.

35. Brodie JF, Giordano A: Lack of trophic release with large mammal predators and prey in Borneo. Biol Conserv 2013, 163:58-67.

36. Mote PW, Hamlet AF, Clark MP, Lettenmaier DP: Declining mountain snowpack in western North America. Bull Am Meteoro/ Soc 2005, 86:39-49.

37. Watson FGR, Newman W, Coughlan JC, Garrott RA: Testing a distributed snowpack simulation model against diverse observations. J Hydrol 2006, 328:453-466.

38. Post E, Stenseth NC: Large-scale climatic fluctuation and population dynamics of moose and white-tailed deer. J Anim Ecol 1998, 67:537-543.

39. MacKenzie DI, Nichols JD, Lachman GB, Droege S, Royle JA, Langtimm CA: Estimating site occupancy rates when detection probabilities are less than one. Ecology 2002, 83:2248-2255.

\section{doi:10.1186/s40665-014-0004-2}

Cite this article as: Brodie et al: Trophic interactions and dynamic herbivore responses to snowpack. Climate Change Responses 2014 1:4. 